I nvestigaciones Fenomenológicas, n. 15, 2018, 109-132

e-ISSN: 1885-1088

\title{
Husserl. Cuerpo propio y alienación
}

\author{
HUSSERL. OWN LIVING BODY AND ALI ENATION
}

\begin{abstract}
Resumen: En este artículo intento aclarar qué significa la distinción yo / cuerpo (propio), en el contexto de los análisis de la constitución de I deas II. Me interesa el énfasis husserliano en la dimensión constituida del cuerpo propio, del cuerpo como «haber» del yo en que desembocan las descripciones del cuerpo vivido. Esta posesión señala una condición antropológica fundamental y entraña la posibilidad de su enajenación o no reconocimiento. En un primer momento describo la esfera vivida del cuerpo propio, su condición animal en los términos husserlianos de la segunda parte de Ideas II; en el segundo apartado expongo la problemática de la constitución de la propiedad del cuerpo en relación con los niveles constitutivos del yo (pasivo o activo); finalmente, en un tercer apartado desarrollo los aspectos principales de la alienación o enajenación del yo y el cuerpo a través de experiencias cenestésicas e hiperestésicas en las que la sensibilidad primaria parece opacar la fuerza del yo libre y activo. En cada momento o nivel se muestra el hiatum yo / cuerpo, la condición de una conciencia irreductible al cuerpo y de un cuerpo inapresable en los límites del yo, como conciencia en vigilia.
\end{abstract}

Palabras clave: Corporalidad, transcendentalidad, objetivación, alienación.

\begin{abstract}
In this paper I wish to clarify the I/(own) living body distinction, an issue that arises from constitutive analysis in I deas II. I am interested in Husserlian insistence on the constituted dimension of the own living body, the body as the "have" of I, where all descriptions of living body arrive. This possession points to the fundamental anthropological condition and encloses the possibility of being alienated or not recognized. The first step is to describe the lived sphere of the own body, its animal condition, as exposed in the second part of Ideas II. The second part is aimed at disclosing the constitution of bodily "owness" in relation to different constitutive levels. Finally, in the third part I delve into most important features of alienation of the I and the body through kinaesthetic and hiperaestetic experiences, in which primary sensitivity seems to numb the force of free and active 1 . The hiatum between I and body reveals itself as awake consciousness on every level of constitution, and it is the condition for a consciousness irreducible to the body and a body which is not apprehended in the limits of $\mathrm{I}$.
\end{abstract}

Key words: Corporality, transcendentality, objectification, alienation.

\section{I NTRODUCCIÓN}

La historia y naturaleza de Ideas II complican su lectura tanto como abren sus posibilidades interpretativas. Ideas II puede entenderse en su articulación 
con el proyecto fundamental de la filosofía que atraviesa la crítica de las ciencias. Los objetivos, por ejemplo, de la Lección de 1927 sobre Naturaleza y espíritu ${ }^{1}$ son perfectamente coherentes con la tarea deconstructiva del concepto de naturaleza que emprende Husserl en estos estudios recuperados y organizados por Stein. I deas II establece las bases para clarificar el fundamento de la delimitación entre los campos objetivos de las ciencias del espíritu y la naturaleza, atendiendo a la experiencia diferenciada en la que arraiga el sentido de los objetos comprendidos en cada campo, ya como objetos espirituales o como "mera" naturaleza. La teoría de las actitudes es fundamental en la aclaración de la diferencia constitutiva de los objetos correspondientes a cada región ${ }^{2}$. Husserl deconstruye el concepto de naturaleza hasta localizarlo en el núcleo de la subjetividad personal (espiritual / humana) en el sustrato sensible (primario o pasivo) de la vida individual. Los análisis de Ideas II se despliegan a caballo entre las descripciones estáticas y los problemas de la génesis desde su objetivo central, la explicitación del origen de sentido - en la experiencia- de eso que para nosotros es la realidad natural y que las ciencias simplemente dan por sentado como el mundo en el que encuentran sus objetos y medios y metas de trabajo.

Husserl reconduce el concepto científico de naturaleza a su contenido espiritual, y el concepto espíritu a su génesis en un estrato pre-egoico, donde vuelve a trenzarse con la naturaleza (en el sentido de lo predado) que "funciona" pasivamente en el fondo de la vida subjetiva ${ }^{3}$. Husserl desmonta el concepto de naturaleza hasta remitirlo a sus fuentes experienciales básicas, inmediatas en el sentido de pre-científicas. Los análisis de la corporalidad aparecen en relación con la constitución de los cuerpos físicos o espacio-temporalmente constituidos -experimentados- y al hilo de las descripciones de la naturaleza, de la experiencia en su naturalidad. El cuerpo aparece en su peculiar hibridación de cuerpo

\footnotetext{
${ }^{1}$ Husserl, Edmund. Natur und Geist, Netherlands, Springer, 2001. Trad. Franc. Nature et Esprit. Leçons du semestre d'été 1927, París: VRIN, 2017.

2 En la lección de 1927, región ontológica significa una región de ser implica una típica orientación de la experiencia que podemos llamar actitud. Una región ontológica es una "«esfera de ser esencialmente cerrada en sí», «clausurada» de una manera que le es esencialmente propia." Ibíd., p. 56-57.

3 “El espíritu tiene un subsuelo anímico. Éste se muestra en que el sujeto yo no tiene que atenerse a meras retenciones y reproducciones de recuerdo (...) la similitud sensible actúa haciendo nacer nuevas predaciones de especie sensiblemente similiar." Husserl, Edmund. I deas relativas a una fenomenología pura y una filosofía fenomenológica, Libro II, Investigaciones filosóficas sobre la constitución, México: FCE, 2005, Trad. Antonio Zirión Quijano. En adelante Ideas II.
} 
físico y algo más, un plus ${ }^{4}$ o excedencia de la materialidad. El yo es impensable más allá de esa materialidad e irreductible a la causalidad en la que también se inserta. El yo es siempre y necesariamente subjetividad encarnada y, sin embargo, no se localiza en el cuerpo, aunque el yo sea siempre un yo situado, un aquí espacializante, el yo no mantiene siquiera comunidad ontológica con el cuerpo que es su carne ${ }^{5}$. La distinción yo/cuerpo es, al mismo tiempo, la condición de la experiencia del cuerpo como propiedad y haber del yo. Los análisis del cuerpo como constituido, como cosa del mundo, experienciada (en sus peculiarísimas distinciones) entre otras cosas del mundo, hacen visible esta brecha insalvable yo/cuerpo que posibilita la objetivación de la propiedad en cuanto tal, y esta objetivación puede entenderse como un modo de distancia-miento del propio cuerpo y una condición básica de las experiencias de alienación o enajenación del cuerpo vivido. Desarrollo este argumento central en tres momentos principales, en el primero describo las características centrales del cuerpo vivido, en el segundo aclaro la función del yo, en la distinción de sus diferentes niveles o estratos, respecto de la constitución del cuerpo propio, finalmente, en el tercer apartado expongo el sentido de la experiencia de alienación del cuerpo propio en relación con este "yo" descrito en el segundo apartado. El objetivo final de estas páginas es apenas mostrar que la distinción entre los niveles del cuerpo vivido y el cuerpo propio genera instrumentos descriptivos y analíticos de una amplia esfera de la vida concretamente humana en su condición encarnada.

\section{DEL CUERPO VIVIDO}

La naturaleza es primariamente el correlato de la actitud natural que es el modo originario en el que nos encontramos en el mundo. Un mundo entorno atemático e incuestionado, casi anónimo en su obviedad, en el que lidiamos y nos comportamos respecto de los objetos espacio-temporalmente dados y entre

\footnotetext{
4 “LA APREHENSIÓn en a que nos es dado EL HOMBRE EN EL CUERPO HUMANO, en la que nos es dado como personalidad que vive, obra, padece, y en la que nos es conciente como personalidad REAL (...) PARECE CONTENER UN PLUS que no se da como mero complejo de momentos de aprehensión constitutivos." Husserl, Edmund. Ideas II, § 34, pp. 178-179.

5 “No se precisa tal nexo o vínculo, no ya por las conocidas dificultades de tender un puente entre regiones heterogéneas, sino, muy al contrario, por el hecho de que los actos, las vivencias intencionales, han tendido ya desde siempre tal puente: su esencia consiste asimismo en tenderlo." Serrano de Haro, Agustín. "Fundamentos del análisis fenomenológico del cuerpo" en La posibilidad de la fenomenología, Madrid: Editorial Complutense, 1197, p. 188.
} 
los que se distinguen meros cuerpos físicos y cuerpos vivos: Körper y Leib-Körper. El cuerpo vivo no es el cuerpo biológico, ni la carne designa la materialidad del cuerpo, aunque la implica - a través del impulso-. El cuerpo vivo en el más amplio sentido describe lo mismo un nenúfar que un mixomiceto o un paquidermo, un cuerpo vivo es un cuerpo viviente, funcional o vitalmente enlazado a un entorno de otros vivientes y de objetos físicos no vivos. El "mundo circundante" es la red infinita e inmediata de relaciones entre cosas vivas y cosas no vivas. El cuerpo vivo mantiene una continua interacción con cuerpos no-vivos. Las cosas vivas se distinguen porque sus cuerpos se despliegan en un proceso de nacimiento, desarrollo, reproducción y muerte. Las cosas vivas crecen, nacen y mueren a diferencia de las cosas no vivas. Ahora bien. Entre los cuerpos vivos podemos reconocer la más precisa esfera de nuestra experiencia como cuerpos además de vivos, vividos. El cuerpo vivido es de un yo -aun como polo-yo-, es vivido desde una interioridad, es mi cuerpo. Hay una experiencia interior del cuerpo. Husserl distingue entre los niveles de una experiencia externa de la realidad física y una experiencia interna de las realidades anímicas. El alma es la esfera anímica del cuerpo que no se escorza ni se matiza. El alma no es una sustancia en el sentido de la realidad sustancial de la naturaleza: "el alma no tiene un en sí como la naturaleza"6. La distinción ontológica del alma determina una demarcación metodológica entre las ciencias cuyos objetos son cosas físicas y aquellas que laboran con o sobre cuerpos anímicos.

La motivación es, en el nivel del cuerpo vivido, de la realidad anímica, la herramienta adecuada para un análisis de la estructura de la experiencia anímica, de cuerpos vivos motivados ${ }^{7}$ por cuerpos vivos, es decir, puestos en una relación no meramente causal sino anímica y a poco, también espiritual, es decir humana: “El alma es unidad de facultades espirituales edificadas sobre facultades sensibles interiores"8. Esta esfera se funda en el curso o transcurso de las dimensiones cognitivas básicas de la corporalidad: el cuerpo vivido se siente a sí mismo, se mueve por sí mismo, es impulsivo o núcleo de una instintividad pasiva o preyoica, el cuerpo vivido es anónimo para sí. Estas condiciones básicas determinan

\footnotetext{
${ }^{6}$ Husserl, Edmund. Ideas II, § 32, p. 171.

7 "Vemos por ende que bajo el yo espiritual o personal hay que comprender el sujeto de la intencionalidad y que la motivación es la ley de la vida espiritual. Qué es la motivación, ciertamente requiere todavía una investigación más detallada." Ibid., § 56, p. 267.

8 Ibid., § 30, p. 163.
} 
el nivel más complejo de la subjetividad encarnada en un "para sí", es decir, una autoconciencia que se reconoce y se desconoce en su condición encarnada. La propiedad del cuerpo (esta centralidad yoica que la articula) se funda en un nivel cognitivo pre-egoico ${ }^{9}$. La vida de conciencia tiene una estructura estratigráfica en la que lo fundante se corresponde con los niveles o estructuras más básicas de la experiencia, la sensibilidad y el instinto. La unidad del propio cuerpo se constituye a través de estas capas de experiencia que articulan campos de sensación y potencias de movimiento, sensaciones táctiles o ubiestésicas en donde la identidad egoica amanece.

\section{A. EL CUERPO VIVIDO SE SIENTE A SÍ MISMO}

La conciencia despierta en el tacto, el roce de la piel, el toque, palpar es génesis de la conciencia, de ahí brota la vida consciente ${ }^{10}$. El cuerpo sintiente, autosintiente, es el sustrato básico del devenir de la conciencia, el amanecer en la apropiación, control, dominio y reconocimiento del propio cuerpo. La piel, el tacto, es la más básica experiencia, una suerte de núcleo sobre el que se forma un sí mismo "delimitado", diferenciado en su autosensación. El sustrato autosintiente del cuerpo propio es la piel. Las sensaciones táctiles conforman el campo más básico y esencial a la base de la experiencia del cuerpo propio.

En las sensaciones táctiles se manifiesta la diferencia originaria, experiencial, es decir, entre los cuerpos vivos y los cuerpos vividos. Los cuerpos vividos sienten los objetos y se sienten a sí mismos en el tacto de las $\operatorname{cosas}^{11}$. Siento mi cuerpo y las partes de mi cuerpo. Las sensaciones ubiestésicas tienen una localización en el cuerpo del que las sensaciones visuales carecen. No siento en el ojo la

\footnotetext{
${ }^{9}$ Esto pre-egoico es nada más que el devenir pasivo de la conciencia, lo que Husserl denomina «impulso» en el sentido de no tener al yo más que como polo unificante, pero no hay en ese estrato, en la acción así dirigida, una actividad del yo como sujeto reflexivo, como fuerza que emerge precisamente en su oposición al impulso encarnado. Volveré sobre esto más adelante. Ibid, Anexo XII, § 2, p. 391.

10 “El cuerpo solo puede constituirse primigeniamente como tal en la tactualidad y todo lo que se localiza con las sensaciones táctiles, como calor, frío, dolor y similares. También las sensaciones de movimiento desempeñan un papel importante." Husserl, Edmund. Ideas II, § 37, p. 190.

11 "Hay una sensación cenestésica muy peculiar, que es el dolor, que hace que aparezca el cuerpo en sí mismo, de manera que la intensidad del dolor puede romper la transparencia de la carne e impedir que se convierta en órgano de la voluntad. No se interrumpe la constitución del cuerpo, el aspecto cognitivo sigue funcionando, pero la carne ya no es transparente a la conciencia volitiva." San Martín, Javier. "EI contenido del cuerpo" en Investigaciones Fenomenológicas, vol. Monográfico 2: Cuerpo y Alteridad, UNED, Madrid, 2010, p. 186.
} 
aspereza del muro como siento la suavidad de la seda en el tacto del pañuelo, la suavidad del pañuelo es suavidad sentida entre mis manos, "alivia", produce un gozo mínimo cuando lo paso alrededor de mi cuello. Las sensaciones táctiles son el enlace primigenio entre la conciencia y el mundo o, dicho de otra forma, la conciencia despierta al tacto de su entorno: “Es el mundo el que nos toca, objetivándonos, pero a la vez en ese momento, la carne tocada se siente como tal, se hace carne"12. La más básica diferencia entre lo vivo y lo no vivo se reconoce ahí, en el tacto de las cosas, la mesa no responde a mi caricia, en sentido estricto el objeto no se acaricia. La caricia, como crisálida abierta del tacto, es el más íntimo contacto que puede alcanzarse entre subjetividades. Al pasar la mano por la espalda de mi amada, el placer de mi tacto es sentido como placer por ella en su propia piel. Cuando dos cuerpos vividos se rozan, hay en cada uno la sensación propia de la sensación propia del otro. Al palpar la mesa tengo la sensación del objeto, su aspereza, y la sensación de mis dedos en el toque, la molestia localizada en esa región de la piel. Las sensaciones táctiles están en la génesis y límite físico efectivo de la vida de conciencia en su ilocalización e indeterminabilidad material. El hecho es que la conciencia no se agota en la corporalidad, en sus límites materiales perecederos y, sin embargo, es inconcebible más allá de esos límites. Aun los fantasmas tienen su sábana de piel ${ }^{13}$.

\section{B. EL CUERPO VIVIDO SE MUEVE A SÍ MISMO}

Las cinestesias o sensaciones de movimiento están en el núcleo de la diferencia de la constitución de objetos vivos y vividos. Los cuerpos vividos - como el cuerpo humano- que se manifiestan en el movimiento libre o espontáneo, son portadores de una voluntad. Esta voluntad manifiesta toda una esfera de interioridad apresentada en el movimiento libre captado, (posiblemente captado) en la experiencia o el reconocimiento del otro. Si se puede mover por sí mismo se

12 I bíd., p. 182.

${ }^{13}$ En un ejercicio de variación eidética que nos permita localizar los elementos esenciales de la constitución del cuerpo vivido alcanzamos las sensaciones táctiles, como sensaciones en sentido estricto. Es decir que se sienten en el propio cuerpo. Toda fantasía de un alma incorpórea incluye en el modo de metáforas o símbolos un modo de la tactualidad o de la piel. Al imaginar un fantasma, como un alma sin cuerpo, imagino alguna forma suya que correspondería a una variación de su fantasmagórica piel. Ver Husserl, Edmund. Ideas II, § 64, p. 68. 
siente como yo mismo; un "cómo" que expresa la experiencia analogizante del cuerpo del otro supone una identidad del yo personal ya constituida en un mundo. Lo que se analoga es el yo, esa interioridad vivida del cuerpo, no el cuerpo en sí mismo como cosa u objeto ahí. Esto es importante para entender el énfasis de Husserl en lo que significa la unidad de la persona anímica. No se capta el cuerpo como el contenedor de algo más, ni se apercibe un yo como capturado o dentro, como un agregado o parte del propio cuerpo. El hecho es que la experiencia inmediata del otro cuerpo vivido es la de la potencia de su libre movimiento. No hay mediación alguna en ello. Reconozco y distingo los cuerpos vividos de todo lo demás porque reconozco en ellos una libre potencia de movimiento. Es la captación de esta potencia cinética la que me da el cuerpo en su vitalidad.

Las cinestesias y la potencia de movimiento libre están entrelazadas con la constitución de la realidad objetiva formada por objetos espacio-temporales individuales. La pregunta por el cómo se constituye la identidad de los objetos había sido formulada desde I deas I $(\S 13)^{14}$ y ahí Husserl señala que la identidad de la cosa es "conciencia de identidad" — de la cosa-, del objeto en cuanto dado de tal o cual manera. Es una unidad constituida en la corriente de la temporalidad inmanente, y los múltiples actos en los que puede darse uno y el mismo objeto. Al analizar en Ideas II el modo de constitución de los objetos físicos Husserl describe el modo en que esa conciencia de identidad está entrelazada con la posibilidad de libre desplazamiento en torno al objeto (sensiblemente percibido). Este entrelazamiento expone elementos determinantes de la estructura de la conciencia, el que los objetos espaciales se nos den necesariamente en sus matices implica una tendencia siempre abierta a la plenificación de nuevos (y siempre posibles) perfiles del objeto. La posibilidad de plenificación está fundada en protenciones, anticipaciones eslabonadas con el curso de percepción actual que las sostiene y que supone la capacidad de que yo de la vuelta al objeto, estire mi cuello, enfoque mi mirada para ver los detalles que a primera vista no distingo, es decir, está enlazada con las determinaciones de mi cuerpo como potencialidades entretejidas con protenciones en las que se ancla la constitución de la identidad de los objetos de la naturaleza como campo de la experiencia inmediata o

\footnotetext{
${ }^{14}$ Husserl, Edmund. Ideas para una fenomenología pura y una filosofía fenomenológica. Libro primero: Introducción general a la fenomenología pura, México: F.C.E., 2013, § 13, p. Trad. Antonio Zirión Quijano.
} 
no mediada por presunciones científicas (pre-científico sería en este sentido sinónimo de "natural", ordinario). La conciencia del tiempo y del yo se "trenza" originariamente con la condición cinética del propio cuerpo. La espacio-temporalidad como condición sintética de la percepción sensible entrelaza la potencia espacializante del propio cuerpo con el transcurso temporal del acto perceptivo.

La potencia automoviente del cuerpo y el movimiento de nuestras acciones ordinarias se despliegan pasivamente. No es necesario que calcule la fuerza con que debo empuñar el picaporte para girarlo, o los pasos que debo dar hasta la puerta para salir de la habitación. Se trata de una acción pre-reflexiva, correspondiente al estrato de naturaleza al que también pertenece el propio cuerpo, entendida, pues, en su sentido de naturaleza pre-dada ${ }^{15}$. El movimiento es tan voluntario como impulsivo, entretejido con habitualidades que imprimen un estilo propio e individuación efectiva al libre desplazamiento. El impulso es pre-egoico, pero, como toda esta esfera, permanece como núcleo del despliegue histórico del yo. Husserl llama sustrato sensible a este estrato primario de la vida de conciencia que el yo envuelve y de alguna manera subsume. Este núcleo incluye el instinto.

\section{EL CUERPO VIVIDO ES INSTINTIVO}

El instinto se entiende como lo innato ${ }^{16}$, lo que corresponde de suyo a la condición natural pre-dada del cuerpo, irreductible o nunca plenamente domeñable por el yo, siempre en tensión con la voluntad que se forja en torno al instinto:

El yo personal se constituye en la génesis primigenia -afirma Husserl- no solamente como personalidad determinada impulsivamente, desde el comienzo y siempre impulsada también por instintos primigenios y siguiéndolos pasivamente, sino también como

\footnotetext{
${ }^{15}$ En Ideas II y, en términos amplios, en el contexto del esfuerzo husserliano por el deslinde de los campos objetivos de los saberes científicos, pueden distinguirse al menos tres sentidos del concepto de naturaleza (referidos a un mismo núcleo de realidad). El primero es la naturaleza en el sentido del correlato de la actitud natural como el entorno de objetos espacio-temporalmente dados; el segundo como concepto científico abstracto o vaciado de todo contenido espiritual y el último, como correlato de la actitud trascendental, la naturaleza como la condición predada del horizonte del mundo.

${ }^{16}$ Ver Hart, James G. “Genesis, Instinct, and Reconstruction: Nam-In Lee's Edmund Husserl's Phänomenologie der Instincte", en Husserl Studies, 15, 1998, pp. 101-123.
} 
yo superior, autónomo, libremente actuante, guiado en particular por motivos de razón no meramente arrastrado y no libre ${ }^{17}$.

La propiedad del cuerpo se forja perfilando al yo, el yo no pre-existe al cuerpo, más bien la experiencia del cuerpo narra el devenir del yo, en este perpetuo distanciamiento del sustrato de una sensibilidad que en este proceso de domesticación permanece siempre en su anonimato. Husserl llama sustrato de la sensibilidad a un núcleo pasivo que está en el origen de la constitución del cuerpo propio. Este sustrato señala una esfera no egológica, que en los Anexos define como la de un yo dormido o pasivo. ${ }^{18}$ El yo activo, despierto o de la voluntad se constituye en el núcleo de la vida personal, en la resistencia a la fuerza del impulso y el instinto o su imperativo corporal. El yo de la voluntad actúa en un nuevo plano experiencial del cuerpo propio, mediado por la reflexión, como un acto que representa de hecho una escisión y polarización entre el yo actuante y su cuerpo como su haber en su esencial condición anónima.

El cuerpo vivido es esencialmente anónimo y su vitalidad automoviente, autosintiente e impulsiva es pre-egoica. El sentido no egológico del cuerpo vivido, su dimensión de carne, designa al mismo tiempo su condición anónima. El cuerpo en tanto órgano de movimiento, sintiente y autosintiente, no es tema sino dimensión básica de la experiencia. No hace falta reflexión alguna que calcule anticipadamente la extensión, duración o fuerza de mis movimientos corporales en el curso ordinario de mis acciones, la extensión de mis pasos o la fuerza de mis empeños físicos. Entrar en un lugar, salir, andar por la calle. Nada de esto implica alguna clase de reflexión previa o cálculo simultáneo. El cuerpo como unidad funcionante, como cuerpo vivido tiene un núcleo de sensibilidad básica respecto de la que el yo no tiene ni cobra incidencia alguna; no hay determinación alguna de mi yo, de mi voluntad, mi cuerpo no cesa de ser afectado por la atmósfera, la temperatura, el hambre, la sed, la intensidad del sonido, el silencio o la luz, etc. Pero mientras su afectación no alcance un nivel insoportable o excesivamente incómodo, el cuerpo mantiene su anonimato, se mantiene en el flujo o corriente de la sensibilidad atemática, que funciona como telón de fondo de toda experiencia

17 Husserl, Edmund. Ideas II, § 59, p. 302.

18 “Tenemos ahí afección de yo y reacción «inconcientes». Lo afectante llega al yo, pero no al yo en vigilia, al yo del volverse u ocuparse «consciente», etc." Ibid., Anexo XII, § 2, p. 391. 
efectivamente temática, reflexiva, volitiva y libre. Mientras el cuerpo funciona, su anonimato fluye, cuando el dolor (o el gozo) traen el cuerpo a un primer plano, el yo entra de tal modo en tensión con su propio cuerpo, que puede alcanzar un estado irreconciliable. Esto es posible por la originaria distinción que, en el cuerpo vivido, germina entre el yo y el cuerpo y, concretamente, respecto de un yo despierto, una voluntad encarnada y egocéntrica, autorrefleja y, por ello mismo, autoescindida de su cuerpo como fuerza instintiva sorda y anónima. ¿Es posible bajo estas condiciones clarificar una sutil pero dramática distinción entre el cuerpo vivido y el cuerpo propio a ras de la diferencia ontológica del yo?

\section{DEL CUERPO PROPIO}

El cuerpo propio es un cuerpo físico (espacio-temporalmente dado) vivo, vivido y propio, es decir, cuerpo de un yo. El yo es impensable sin un cuerpo, es ya siempre y necesariamente devenir encarnado de la voluntad de movimiento. Pero el alma, la vida anímica es en un amplio sentido vida animal, la vida espiritual concretamente humana, personal, una animalidad egocéntrica.

Todo cuerpo anímico tiene un alma, una vida anímica, pero no necesariamente toda alma llega a ser un yo o un yo reflejo, autoconsciente. El yo anímico es el alma, son los sujetos animales que tienen vivencias y estados anímicos vinculados al cuerpo. El sujeto anímico está referido a las vivencias anímicas de tal modo que él las tiene, pero estas vivencias no son sus propiedades sino sus maneras de comportamiento ${ }^{19}$.

La propiedad del cuerpo se constituye en el mismo movimiento en que se forja la identidad yoica en su centralidad personal. La propiedad yoica del cuerpo se funda en su gobierno, en el acto libre que domina el cuerpo convirtiéndolo en órgano de una voluntad fundada en la autonomía cinética, sí, pero una voluntad ya no sólo corporal sino egoica en sentido pleno. La propiedad es apropiación comprensible en este despliegue activo del yo que se impone como voluntad centrada sobre su cuerpo, lo hace suyo apropiándoselo en el freno que pone a la acción impulsiva o mecánica, irreflexiva o pre-reflexiva. El cuerpo como propiedad del yo emerge en la vigilia del yo que se opone como una fuerza de

19 Husserl, E., Ideas II, § 30, p. 160. 
resistencia al impulso. El yo despierta como fuerza opuesta a la impulsividad del cuerpo, como potencia de autogobierno a través del cuerpo. ${ }^{20}$ La propiedad es apropiación en la dominación de un sí mismo corporal. Husserl propone un ejemplo bastante claro. El impulso de un fumador mientras trabaja. Yo puedo estar frente a la pantalla de la computadora escribiendo o leyendo con cierto grado de concentración en el texto, en lo dicho. Siento el impulso de fumar y busco en el escritorio el tabaco hasta encontrarlo, encenderlo y quemarlo entre mis labios. Todo este curso de acciones corporales obedeció a un impulso, una serie de habitualidades del movimiento, y la estructura de mi entorno inmediato de desplazamiento, etc. Pero ninguno de estos actos, ni en su individualidad ni en su unidad ha sido propiamente de un yo libre y despierto, sino que se han desarrollado mecánicamente, bajo cierto nivel de pasividad ${ }^{21}$. Es probable que la clarificación misma del sentido de esta propiedad dependa de la distinción entre dos niveles de la vida de conciencia - de esta conciencia encarnada- que Husserl describe como conciencia despierta y conciencia sorda, estrictamente equivalente a un yo en vigilia y un yo dormido 22 . La propiedad del cuerpo es el correlato en «tensión» de un yo libre o en vigilia. El yo despierto tiene un cuerpo en el momento mismo en que se impone sobre él como voluntad. El yo libre se constituye en una acción no gobernada por el impulso o el instinto sino por valoraciones, juicios y motivaciones de razón que preceden la libre decisión del yo, es libre porque es del yo y no del impulso. El yo aparece como resistencia al curso «mecánico» de la vida, por ello se gesta y realiza en la experiencia, como un yo hago comprensible en el tejido de motivaciones que articulan la unidad corporal del sujeto. La diferencia recae aquí entre cuerpo vivido y yo. En la vigilia se distinguen estos dos planos

\footnotetext{
20 “Capto entonces la esencia del «yo resisto», «yo empleo mi fuerza de yo (energía)» y «hago», la acción brota entonces del «yo mismo». Capto precisamente de esta manera la esencia del fiat negativo: «yo rehúso mi asentimiento práctico al estímulo que me distrae». Pero también la tensión entre ambas «fuerzas», aumento de la acción de la voluntad (...) frente al estímulo eventualmente también creciente." Husserl, E., Ideas II, Anexo XI, p. 380.

${ }^{21}$ Es probable que haya que distinguir aquí entre el flujo pasivo de la conciencia, la archipasividad, y la pasividad del instinto, entretejida en las habitualidades del sujeto y su entorno significativo. El yo no se opone aquí a la «pasividad», sino a la fuerza de un impulso arraigado en el cuerpo, trenzado con habitualidades y motivaciones pasivas. Surge el impuso de la corriente misma de la pasividad, pero no se opone a ella, brota de ella como cualquier rayo o acto de la conciencia. El impulso es pasivo en la medida en que es pre-egoico pero no es la pasividad, sino un sustrato de esta.

22 “El yo durmiente en oposición al despierto es la completa inmersión en la materia-de-yo, en la hyle, el ser-yo inseparado, el hundimiento-del-yo, mientras que el yo despierto se contrapone a la materia y es así afectado, hace, padece, etc." Husserl, E., Ideas II, § 58, p. 301.
} 
del cuerpo, el cuerpo vivido y el propio. El yo puedo es sujeto de capacidades físicas y espirituales ${ }^{23}$. Las primeras abarcan el dominio de sí sobre los propios movimientos, el yo sintiente que reconoce su condición y diferencia entre otros cuerpos. De las capacidades físicas se distinguen las capacidades espirituales; entre las más básicas está el poder recorrer libremente la corriente de mi vida y mis distintos modos de ser y experimentar el mundo. El yo espiritual también como el cuerpo- se comprende como órgano de capacidades ( $\S 59$ ). Es capaz de recorrer libremente la corriente de vivencias que le es propia, le es posible objetivar su propia experiencia24. El yo es capaz de ver su propia vida, y ver en el sentido de la captación fenomenológica de sí mismo, de los otros que le rodean y con quienes co-constituye su mundo; el yo está ya siempre habitado por el otro; desde su cuerpo - como órgano espacializante- el mundo está poblado por los demás. ${ }^{25} \mathrm{El}$ cuerpo se forja en una trama cultural o intersubjetiva.

El centro egoico, el yo de los actos corporales, del desplazamiento y las sensaciones, es quien vive ese cuerpo, quien tiene un cuerpo y lo tiene incluso como su haber. El yo hace de la corporalidad viviente una corporalidad vivida. Lo que esto supone a nivel de las estructuras trascendentales de la vida representa el punto de quiebre de la antropología del cuerpo. Un cuestionamiento que demanda la presencia central de un yo que intenciona, objetiva y experimenta su propio cuerpo como objeto y tema; que envuelve al cuerpo desde él mismo: “EI cuerpo es mi haber"26. El problema fenomenológico recae sobre la condición de

23 “YO COMO SUJETO DE MIS DECISIONES, de mis tomas de posición, de mis resoluciones y mis firmes posiciones hacia éstas o aquellas cuestiones, nacidas de tomas de posición primigencias, instituyentes; y en conexión con ello: yo como sujeto de motivaciones en el sentido específico de que me dejo motivar así y asá por especies respectivas de motivos para tomar tal o cual posición." Husserl, E., Ideas II, Anexo XI, p. 381.

24 “Aquí, la objetivación representa ninguna operación negativa -alienación o extrañamiento- sino que debe entenderse como un rasgo estructural necesario de toda experiencia mundano-fenoménica. Esto es, que el hecho de que nos auto-objetivemos y objetivemos a otros seres humanos o vivientes en la percepción, esta percepcion permite distintas formas de abuso, violencia y maltrato, pero la objetivación perceptiva en cuanto tal no es un acto de violencia." Heinämaa, Sara. "The Many Senses of Death: Phenomenological Insights into Human Mortality", en Hakola, Outi, Heinämaa, Sara, and Pihiström, Sami (eds.). Death and Mortality - From Individual to Communal Perspectives, Studies across Disciplines in the Humanities and Social Sciences, Helsinki Collegium for Advanced Studies, 2015, p. 103.

25 “En cualquier etapa de esta fase de la constitución, la mónada, propiamente hablando, no está en ninguna parte. Sin embargo, al haberse obtenido una determinada conjunción de mónadas, para cada una, a través de un sistema ordenado de modificaciones se constituye es una especie de espacio común." Lobo, Carlos. "Self-Variation and Self-Moditification of the Different Ways of Being Other" en Jensen, Rasmus Thybo and Moran, Dermot (eds.), The Phenomenology of Embodied Subjectivity, Switzerland: Springer, 2013, pp. 263-283.

${ }^{26}$ Husserl, Edmund. Ideas II, § 57, p. 
este haber, sobre su significado constituido. ¿Qué es este "haber" en los términos experienciales en los que primariamente se manifiesta? ¿Qué significa la experiencia del cuerpo como haber del yo?

El concepto fenomenológico del yo, como la noción o concepción misma de la identidad subjetiva, implica el descubrimiento de una nueva estructura tanto como una resignificación de los términos de la tradición en el contexto subjetivista. Fenomenológicamente, el yo, la unidad idéntica de la vida subjetiva, es siempre una «identidad descentrada», desgarrada en un movimiento centrífugo y objetivante, sí, en un acto de "apropiación por desapropiación":

La apropiación de la subjetividad intentada por Husserl —señala Hans R. Sepp- producía justamente lo contrario de lo buscado. En lugar de una apropiación del sí mismo conducía a su abandono, a una desapropiación de la respectiva existencia, y, por consiguiente, lleva al extremo aquella instrumentalización de la efectuación de la vida (Lebensvollzug) que se instala en la filosofía moderna. ${ }^{27}$

La fenomenología se sitúa más allá o en un plano anterior a cualquier subjetivismo, su radicalización estriba en dar con la vida. El yo idéntico en todos sus momentos, en sus manifestaciones abiertas a sus modos de contemplación es un yo autoescindido ${ }^{28}$, fracturado y concretado en su puesta a distancia de sí: “¿Qué significa esta escisión y esta identificación propia del yo en la reflexión, del yo objetual y simultáneamente anónimo? ¿Es esta la sola y única posibilidad de ser consciente de sí? Pero aun escindiéndose, este yo permanece siempre el mismo"29. Esta mismidad se revela en un acto que la altera, la hace otra o la pone a distancia respecto de la básica y más elemental unidad del yo activo, el yo que lleva a cabo el acto de reflexión. Se mantiene pues esta no-coincidencia originaria entre el yo reflejo, encarnado, y el yo actuante desde su condición

27 Sepp, Hans Rainer. "Apropiación por desapropiación. Paradojas de la reducción fenomenológica" en Escritos de Filosofía, Academia de Ciencias de Buenos Aires, No. 35-36, 1999, p. 3.

28 “Como sujeto de todas estas maneras de comportamiento, el yo puro admite, empero, una aprehensión realizadora, que puede ser ejecutada por un nuevo acto del yo puro en referencia a sí mismo y sus maneras de comportamiento pasadas recordativamente concientes, o que también puede ser ejecutada por un yo puro en actos de comprehensión en referencia a otro." Husserl, Edmund. Ideas II, Anexo X, p. 378.

${ }^{29}$ Brand, Gerd. Mondo, 10 e tempo. Nei manuscritti inediti di Husserl, Valentino Bomplani, Milano, 1960, p. 133. Trad. Enrico Filippini. Título original: Welt, Ich und Zeit. Nach unveröffentlichten Manuskripten Edmund Husserls, M. Nijhoff, La Haya, 1955. 
carnal también. Esta escisión o apropiación por desapropiación es también una condición de la carne, entre la corriente fluyente de la sensibilidad pasiva y el yo activo desde esa misma dimensión: “El punto de partida de la reflexión -afirma Brand- es, en cierto modo, el punto en el que el yo anónimo, que es consciente no objetualmente, se convierte en un yo que se mantiene y se hace consciente de modo objetivo"30. El «milagro de la conciencia» es esta potencia de iteración, repetición del sí mismo, de un sí mismo del pasado y en su condición corporal ${ }^{31}$.

El cuerpo propio es el de un yo capaz de este saber de sí, en y desde la condición encarnada de su propia vida. Pero al mismo tiempo la propiedad representa una no coincidencia plena entre ese cuerpo apropiado y el yo. Y es que el cuerpo, en efecto, es apropiado, constituido, experienciado en su ser parte del mundo. El yo va colonizando el cuerpo y este devenir histórico es lo que Ideas II describe. La distinción que intento establecer entre cuerpo vivido y cuerpo propio recae en el yo descentrado, en el movimiento centrífugo en el que el yo también se constituye, a la par que su cuerpo; antes del yo y en la pasividad del yo hay un cuerpo vivido, pero no necesariamente un cuerpo propio como órgano de una voluntad lúcida o egocéntrica, bajo la condición de esa centralidad descentrada 32 .

El cuerpo como propiedad es objeto y expresa la apropiación su condición de ser cosa en y del mundo. El objeto, además, es simultáneamente el sujeto, por lo que no podemos dar por sentada la «mera» naturaleza cosificante de sí que acarrearía la autorreflexión así pensada. Lo que salta a la vista es más bien esta doble dimensión de la vida de conciencia, la duplicidad de una conciencia viviente y una conciencia refleja dada en una vivencia peculiar dentro de la corriente temporal de la vida: "Si la subjetividad es el fenómeno, por excelencia, puesto a la luz por la reducción fenomenológica, esta se revela tanto en su duplicidad como en su unidad, tanto en su entorno simbólico como en su unicidad, tanto en

${ }^{30}$ Brand, Gerd. op. cit., p. 136., alemán, p. 70.

31 “El yo se hace frente a sí mismo, es para sí mismo, constituido en sí mismo. Cada yo puede también hacer frente a uno o varios otros yos, ser objeto constituido para ellos, aprehendido, experimentado por ellos, etc. Pero precisamente también es constituido para sí mismo y tiene su mundo circundante constituido." Husserl, Edmund. Ideas II, Anexo VII, p. 369.

32 "Ciertamente este yo puede también fungir como tal enfrentante. Entonces TIENE en cuanto yo su enfrentante y a la vez ESTÁ haciendo frente a otro yo o en la reflexión a sí mismo. Pero no-yo, el objeto que no es sujeto, es lo que es sólo en cuanto enfrentante, solamente en cuanto algo constituido con referencia a un yo o a una pluralidad abierta de yos y sus peculiaridades primigeniamente yoicas." Husserl, Edmund. Ideas II, Anexo VII, p. 369. 
su facticidad como en su tendencia a lo supratemporal"33. La apropiación es habituación del cuerpo, domesticación y espiritualización corporal. El cuerpo en cuanto propiedad no es anterior a la incidencia efectiva de la vida espiritual en su prefiguración. La apropiación es intersubjetiva y espiritual, cultural o histórica. Se trata de dimensiones que se trenzan y perfilan el cuerpo y el despliegue mismo de la apropiación. En ello los hábitos - que son del yo- juegan un papel fundamental. La habituación es encarnación, donde nace el yo como persona, entre los hábitos y el cuerpo, y totalizante de ambas dimensiones. La condición histórica del yo personal humano sintetiza ambas esferas sin opacar las diferencias del cuerpo y la vida psíquica, del yo y la carne. La apropiación del cuerpo es un gesto o movimiento espiritual primario de la vida de conciencia.

Para Marx la historia comienza en el trabajo, la apropiación de la naturaleza a través del cuerpo, del esfuerzo. El devenir histórico de la persona como una identidad egoica, una subjetividad encarnada, implica en su génesis esta suerte de rebasamiento de la causalidad a la que pertenece el cuerpo, por la voluntad en la que el yo se realiza, vuelto siempre hacia lo otro de sí. Desde este punto de vista, Husserl cava más profundo y llega a donde Marx no alcanza: el primer esfuerzo, acto voluntario en que comienza la historia del yo, es el esfuerzo sobre el propio cuerpo, laborar sobre el cuerpo como apropiárselo; nace el yo en esta primera apropiación. El cuerpo aparece, en su condición de cosa en el mundo como lo otro de sí y el acto de apropiación es al mismo tiempo enajenante, establece una distancia irremediable que distingue la conciencia y el cuerpo. El yo es su cuerpo, pero además tiene un cuerpo y esta posesión en el sentido mismo de su constitución, de la propiedad en cuanto tal, establece una distancia que posibilita al mismo tiempo la desposesión o alienación del cuerpo propio. La intencionalidad sólo expone la diferencia originaria en el seno de la experiencia de sí. El cuerpo propio que es cuerpo de un yo es también algo distinto y no coincidente, en el acto mismo, con el yo ${ }^{34}$. En la autopercepción el cuerpo propio se distancia de sí mismo en su condición de cuerpo vivido. La propiedad del cuerpo

${ }^{33}$ Bernet, Rudolf. La vie du sujet, Paris: Presses Universitaires de France, ,1994, p. 3.

34 "Ahora es evidente que no puede sostenerse en modo alguno que lo propiamente yoico sea experimentable en el cuerpo o dentro del cuerpo, que sea algo unido con él a la manera de un estrato constituido en el interior de una objetividad constituida. Toda objetividad y estrato semejante pertenece, en efecto, al lado del no-yo, de lo enfrentante, que solamente tiene sentido como enfrentante de un yo." Husserl, Edmund. Ideas II, Anexo VII, p. 369. 
es el correlato de un yo que se auto-objetiva a través de la carne, desde la carne, como un yo activo o en vigilia.

Pasividad y actividad son dos niveles de la vida egoica, el primero en realidad pre-egoico e impulsivo, una conciencia sorda fluyente en una corriente de pura sensibilidad; pensemos, por ejemplo, en una medusa o una estrella de mar, en un feto o un lactante que no tienen un yo ni una personalidad autorrefleja en general. Hay un proto-yo en el lactante, cuyo cuerpo de hecho no se limita en el cuerpo de la madre, sino que le corresponde como un continuum dependiente. Hay una esfera de protocapacidades del sujeto anterior a la actualidad de la experiencia que se distingue del plano de las capacidades adquiridas, y que es, por decirlo de algún modo, anterior a la experiencia. En el $\S 58$ Husserl afirma que el yo no es primigeniamente a partir de la experiencia sino a partir de la vida, el yo deviene en la vida ${ }^{35}$. La forma de la subjetividad se constituye en un desarroIlo. El sí mismo no es algo constituido sino algo latente para sí. Yo, el que soy como sujeto, soy distinto, aunque el mismo que soy para mí como objeto, en ese para mí reside el resto inapresable de la vida que desborda continuamente la experiencia, esta experiencia ya aquí del mundo, en el mundo, en la vida que incesantemente fluye incluso cuando se apresa a sí misma en una experiencia de su límite. La continua temporalización autosintiente de la carne permanece como sustrato básico de los hábitos del yo. El yo personal se constituye en la génesis primigenia como personalidad determinada impulsivamente por instintos primigenios que se entrelazan en los actos de un yo superior, autónomo, libremente actuante y guiado por motivos de razón, no meramente arrastrado por los impulsos o su pasividad. El yo despierto es resistencia y oposición a la fuerza del impulso, un yo en vigilia es una persona en un mundo espiritual, entre otras personas, entre otros cuerpos vivos y vividos y otros cuerpos propios como mi propio cuerpo. La apropiación implica ya un estrato de alienación en el que la experiencia del cuerpo sería la de un cuerpo vivo, vivido, propio, y otro para sí.

\section{DEL CUERPO OTRO}

\footnotetext{
35 “El yo no se constituye primigeniamente a partir de la experiencia - en el sentido de la apercepción asociativaen la cual se constituyen unidades y multiplicidades del nexo-, sino a partir de la vida (es lo que es no PARA el yo, sino él mismo el yo). Husserl, Edmund. Ideas II, § 58, p. 300.
} 
La alienación del cuerpo propio es una posibilidad dada en la estructura disonante del yo y el cuerpo, que se manifiesta en el yo despierto como resistencia al impulso. El yo no es aquí el mero yo psicológico, no es el alma aunque la supone, no es la conciencia despierta aunque ahí se concreta como yo libre. El cuerpo, la carne autosintiente, no es el cuerpo orgánico o meramente físico determinado en su funcionalidad biológica. Ese cuerpo es cuerpo vivido y realidad anímica que se despliega desde un estrato de materialidad pura, como condición predada de la experiencia en su núcleo, es decir, no en el sentido científico de una realidad causalmente reducida. El cuerpo vivido forma parte de la realidad viva y vivida de la naturaleza, es afección en un primer y permanente núcleo de su devenir histórico. El cuerpo vivido es mi cuerpo, fenomenológicamente descubierto desde su esencial anonimato. Y aun sobre la relativa claridad que puede arrojarnos esta determinación del cuerpo propio en este registro, la no-coincidencia entre el yo y el cuerpo es igualmente originaria. La conciencia yoica es infinita, el cuerpo propio es finito y mortal. Este hiato insalvable se manifiesta en el acto intencional que objetiva el cuerpo y en la distancia que impone -como cualquier acto intencional- su reconocimiento, distancia entre el yo del acto y el objeto del mismo. La objetivación del cuerpo tiene, sin embargo, un sustrato elemental o basiquísimo en esta no coincidencia originaria entre lo conciencial y lo corporal.

La enajenación del cuerpo implica una ruptura del anonimato y una disrupción del flujo normal de la dimensión cognitiva del cuerpo propio. Las sensaciones de dolor o placer hacen manifiesta la unidad estesiológica del cuerpo pero no en el modo de la posesión, sino de la «alteración», en el dolor paralizante o el éxtasis avasallante, la voluntad más básica se disuelve en la imposición extraordinaria del cuerpo, de su presencia.

El anonimato del cuerpo se manifiesta en las sensaciones cenestésicas, en el dolor agudo el cuerpo se paraliza o se vuelve objeto de obsesión, ocurre una desidentificación del cuerpo y el yo, aparece el hiato originario de la conciencia y el cuerpo se hace visible, se exhibe en una experiencia que evidencia las condiciones de posibilidad, la estructura sobre la que se funda, en estratos de experiencia más complejos o concretamente espirituales, la posible desidentificación absoluta del yo respecto de su cuerpo o de partes de él. La experiencia cenestésica del cuerpo propio lo trae a presencia como mío, pero al mismo tiempo 
impone la distancia de una voluntad incumplida, una ruptura de la expectativa más básica, sobre la que se funda toda otra expectativa en los términos protentivos que atraviesan la experiencia de objetos de la naturaleza física, a la que pertenece mi propio cuerpo. El cuerpo aparece entonces como un obstáculo para ese cumplimiento no solamente aplazado sino roto, en el dolor que impide el movimiento, se produce una imposición del cuerpo sobre el yo, opacamiento, negación o tachamiento de la voluntad, choque de un movimiento de la conciencia que se ve a sí misma en su impedimento frente al cuerpo vivido. En el dolor se exhibe esa originaria distancia que media entre el yo y el cuerpo, y brota en su complejidad una experiencia, enteramente corporal, que parece sólo descriptible a través de la paradoja que supone afirmar que un yo sin cuerpo es impensable, pero en el dolor ese sí mismo se «siente» enajenado de su propio cuerpo.

Lo importante es el hiato, la brecha visible ahí entre el yo y el cuerpo. Es impensable un yo no encarnado pero el yo no se agota, ni siquiera se localiza en el cuerpo. Yo soy mi cuerpo y, sin embargo, no es pensable una comunidad ontológica entre la mera materialidad, condición física y natural innegable del cuerpo y la condición anímica real de esa condición vivida, interna del cuerpo. Yo no sólo soy mi cuerpo, sino que además tengo un cuerpo. El dolor no es un acto intencional, desde luego, el dolor es lo que se padece, se padece el cuerpo, pero en la manifestación cenestésica e hiperestésica del cuerpo se funda de hecho la posibilidad de su objetivación, incluso en el sentido de la actitud naturalista. No hay una experiencia efectiva de dos planos de realidad, una puramente material y otra puramente anímica en la experiencia del otro, y de mi propio cuerpo. La unidad anímico-corporal de la vida subjetiva es constituida en la experiencia misma, corresponde al modo concreto en el que experimento el cuerpo del otro y mi propio cuerpo. $\mathrm{Y}$, sin embargo, la presencia del otro no se agota en la presencia en carne y hueso de su cuerpo, o decir en carne y hueso implica ya esta excedencia continuamente a-presentada - a-percibida - en la experiencia del otro. A-presencia es presencia de lo que no se da. Es no-presencia, lo que no se 
presenta. Sobre lo que no se da recae el mayor peso de la experiencia del otro, a nivel, o a través de la experiencia de su cuerpo ${ }^{36}$.

Cuando el cuerpo sale de su condición anónima y se convierte en dirección primaria o tema de la experiencia del yo, "entonces el mundo desaparece del campo de atención. Nuestro horizonte pierde su sentido. Es una fuerza centrípeta que opaca todo lo demás"37. La alienación representa una posición del yo respecto de su propio cuerpo en dos niveles principales: en el primero, como en el caso del dolor agudo, el yo se desplaza a un segundo plano por la desbordante experiencia de la presencia sentiente del cuerpo en el dolor agudo, el yo es una suerte de testigo en resistencia que tiene su propio cuerpo como un obstáculo e impedimento. El cuerpo es enemigo del yo. No solo se hace patente esa diferencia originaria, irreductible entre el yo y el cuerpo, sino que se profundiza al grado de la escisión rotunda del yo del dolor respecto de su propio cuerpo, un no-reconocimiento que reclama un cese definitivo. El yo como rehén de su propio cuerpo en el dolor y la enfermedad es el centro de una irradiación opaca ya no sobre el mundo, sus objetos, el horizonte, sino cerrada sobre sí, sobre las capacidades bloqueadas o cegadas de la subjetividad corporal. El dolor destruye la condición auto-moviente del propio cuerpo, aunque sea por un momento, el cuerpo que soy me es ajeno, indomeñable. Frente al dolor la voluntad no puede nada. El nivel de la sensibilidad es entonces el plano primario en el que esta experiencia de alteración como devenir «alter», otro más bien ajeno, lo ajeno primero, lo enajenado más bien (si lo que trato de describir es la enajenación como un curso de experiencia) caracterizado por una ruptura radical, una escisión, al interior del cuerpo doliente. El yo ya no se encuentra en su cuerpo, su cuerpo es otro para el yo en el dolor que se prolonga inundando la vida entera de quien lo padece.

El segundo nivel implica, no una resistencia, sino una entrega a la absoluta pasividad de la corporalidad sintiente. En este plano el placer sensible pensado como éxtasis pone al yo en la situación de espectador de una corriente sensible que inunda al yo, toma su voluntad. Este yo cede, lo que no ocurre con el yo del dolor; y en ese ceder la voluntad al gozo estriba su génesis, no antes, antes

\footnotetext{
${ }^{36}$ Quizá no se trata solamente de que la experiencia del otro pueda quedar reducida a los términos de la imposibilidad del darse. Todo el campo de lo apercibido queda abierto a una exploración más profunda, y una clarificación de la paradoja que subyace a la a-percepción como tal.

37 Svaneaeus, Fredrik. "The phenomenology of chronic pain: embodiment and alienation", in Continental Philosophy Review 48 (2), Springer, June 2015, p. 116.
} 
siempre puede ser resistencia al placer y por lo tanto tensión del yo despierto. En este ceder ante el placer hay una libre entrega no súbita al placer. El placer se distingue, de acuerdo con Husserl, en placer espiritual y placer sensible: “Quizá sea terminológicamente mejor distinguir - afirma Husserl- entre sensibilidad propia e impropia, y por este último lado hablar también de sensibilidad intelectiva o espiritual y por el primero de sensibilidad sin espíritu"38. El placer sensible, de cualquier forma, está siempre penetrado y trenzado con el placer o gozo espiritual que es motivado está fundado en valoraciones y sedimentaciones que generan expectativas y tendencias experienciales concretas. En el placer el yo cede porque el contenido del placer sensible es puesto por él, no pertenece en sí mismo a la corriente sensible o corporal y más bien incide en ella.

La enajenación responde a este hiato originario entre el yo y su cuerpo. La unidad manifiesta de la corporalidad desborda los límites de la res en su polarización material / inmaterial, o extensa inextensa. Pero además la unidad no representa una reducción entre polos, sino que permanecen claras sus distinciones, la vida anímica no se escorza, la presencia del alma no se matiza ni se da fragmentariamente, el cuerpo es extenso y por ello fragmentable, fracturable. La conciencia es infinita, el cuerpo es finito y mortal. Es impensable un yo sin cuerpo, pero la conciencia no tiene una localización precisa en el cuerpo ni se capta como limitada a él. La percepción del cadáver es un claro ejemplo del modo en que esta diferencia se mantiene como distinción percibida en la percepción misma de la unidad.

La enajenación depende de esta condición de la unidad cognitiva, porque es esta la unidad que se rompe sacando a flote las condiciones de su anonimato, pero de tal modo que se revelan en su subversión. El cuerpo propio se manifiesta en una necesidad e impulso de su negación. El cuerpo es propio, es mi propio cuerpo y, al mismo tiempo, es otro que se me opone en el dolor o me opaca en el placer: "El dolor nos hace sentir nuestro propio cuerpo de tal modo que es obvio que es mi cuerpo, pero es, al mismo tiempo, ajeno: más allá del control de la persona"39.

La enajenación, esta especie de visión dualista sobre el sí mismo, no es una experiencia extraordinaria ni demanda una meditación metafísica, sino que forma parte de la experiencia natural que tenemos del mundo y de nosotros

\footnotetext{
${ }^{38}$ Husserl, Edmund. Ideas II, Anexo XII, § 2, p. 387.

${ }^{39}$ Svaneaeus, Fredrik. art. cit., p. 121.
} 
mismos en el horizonte del mundo y entre los otros, si bien es la descripción fenomenológica donde se exhibe. Y se trata solo de una proto-enajenación, de la condición estructural que funda actos más complejos y culturales (o espirituales) en los que se discurre sobre la no coincidencia y se explota esa diferencia originaria entre el yo y su carne. Cada sociedad mantiene un régimen de usos y abusos del cuerpo propio y todo un orden sobre las dos dimensiones que caracterizan la existencia social del cuerpo propio, su intimidad y su publicidad. La diferencia originaria entre las funciones constituyentes y la dimensión constituida del cuerpo propio funda a fin de cuentas la distinción espiritual entre el cuerpo propio como lo más íntimo e inalienable y, al mismo tiempo, su irremediable valor público y social. Es probablemente el trabajo y la sexualidad donde se manifiesta con más claridad la tensión entre estos dos polos, público y privado, del propio cuerpo.

La acción intersubjetiva atraviesa el desarrollo entero de la vida subjetiva, como vida personal concreta. La persona es vida trascendental y su cuerpo es órgano constituyente, vida trascendental en carne y hueso. Pero no se confunde con su cuerpo. Su cuerpo es trascendental y trascendente, por lo que es constituido, bajo sus particularidades, como cualquier otro objeto espiritual de los que configuran mi mundo. Es así precisamente porque la conciencia, esta vida que soy yo, no se reduce a su cuerpo, es así porque el cuerpo es constituido por el yo. La condición de la enajenación del cuerpo propio es su propia determinación trascendental y trascendente para sí. El cuerpo vivido es cuerpo vivido y cuerpo para sí:

Es este saber secundario, este conocimiento de sí que nos hace pasar sobre un plano trascendental: la carne corporal a diferencia del cuerpo vivido es conciencia aperceptiva de ella misma como carne corporal. En ella reside la experiencia de una alteridad interna que corresponde al movimiento de la toma de conciencia, es decir a la alteración del sujeto que supone la dinámica de la apercepción ${ }^{40}$.

Esta es la condición que explica su constitución como herramienta, mercancía, medio, otra cosa, órgano de repudio, determinante en su materialidad de

\footnotetext{
40 Depraz, Natalie. Lucidité du corps, Kluwer Academic Publishers, Phaenomenologica, Dordrecht: Kluwer Academic Publisher, 2001, p. 6.
} 
una condición social, porque, efectivamente, la materialidad del cuerpo es lo constituyente y lo constituido, porque nunca ha sido mera materialidad sino mi propiedad, un sentido de propiedad que se forja en el desarrollo del yo espiritual.

\section{CONCLUSIONES}

El cuerpo propio es una dimensión particular del cuerpo vivido que se constituye para un yo de la voluntad, libre o despierto. La apropiación de cuerpo hace al mismo tiempo visible su condición ajena o distinta respecto del yo. Distinta en términos ontológicos. La conciencia es encarnada y corporal, pero en su dimensión antropológica es siempre más que su propio cuerpo, es decir, se reconoce en esa condición, la de su desidentificación. Podríamos resumir el argumento señalando nada más que las condiciones estructurales de la conciencia, que es tiempo, pero no se agota en la descripción de la forma ineludible, absoluta, del transcurso; siempre hay un resto que queda inapresado en una sola de sus determinaciones. La conciencia es carne (corriente autosintiente) pero con todo y su condición absoluta, otra vez, no agota nuestras posibilidades de sabernos, en todas esas condiciones y, sin embargo, siempre en su excedencia. La enajenación del cuerpo es enajenación del yo, es el yo el que aparece en la periferia, en la cuneta de la corriente primaria de una sensibilidad que arrasa el primer plano y todas las distancias del horizonte del mundo. El cuerpo es mío y me es ajeno al mismo tiempo, y esta condición se funda en la doble dimensionalidad originaria del cuerpo vivo, vivido, propio. Su condición de ser objeto constituido y, sin embargo, potencia constituyente del mundo. Yo, esta vida trascendental que soy yo, continua actividad constituyente de sentido del mundo, tengo mi cuerpo y mi cuerpo no es solo parte de la corriente trascendental de la vida, sino que es objeto de experiencia. El cuerpo propio y el cuerpo ajeno son, claro, siempre el mismo cuerpo, como dos dimensiones entretejidas en la experiencia objetivable de mi propia vida. En la posesión del cuerpo germina la dimensión espiritual de la vida humana, de ahí que sea esta apropiación un quiebre antropológico de la fenomenología. 


\section{BIBLIOGRAFÍA CITADA}

BERNET, Rudolf. La vie du sujet, París: Presses Universitaires de France, 1994.

Brand, Gerd. Mondo, lo e tempo. Nei manuscritti inediti di Husserl, Milán: Valentino Bomplani, 1960. Trad. Enrico Filippini.

DepraZ, Natalie. Lucidité du corps, Kluwer Academic Publishers, Phaenomenologica, Dordrecht: Kluwer Academic Publisher, 2001.

HART, James G. “Genesis, Instinct, and Reconstruction: Nam-In Lee's Edmund Husserl's Phänomenologie der Instinkte", en Husserl Studies, 15, 1998, pp. 101-123.

HeInÄmAA, Sara. "The Many Senses of Death: Phenomenological Insights into Human Mortality" en Hakola, Outi, Heinämaa, Sara and Pihiström, Sami (eds.). Death and Mortality - From Individual to Communal Perspectives, Studies across Disciplines in the Humanities and Social Sciences, Helsinki Collegium for Advanced Studies, 2015.

HUSSERL, Edmund. Natur und Geist, Dordrecht: Springer, 2001. Trad. Franc. Nature et Esprit. Leçons du semestre d'été 1927, París: VRIN, 2017.

-, I deas para una fenomenología pura y una filosofía fenomenológica. Libro primero: Introducción general a la fenomenología pura, México: FCE, 2013. Trad. Antonio Zirión Quijano.

-, I deas relativas a una fenomenología pura y una filosofía fenomenológica, Libro II, Investigaciones filosóficas sobre la constitución, México: FCE, 2005, Trad. Antonio Zirión Quijano.

LoBo, Carlos. "Self-Variation and Self-Modification of the Different Ways of Being Other" en Jensen, Rasmus Thybo and MoRAn, Dermot (eds.). The Phenomenology of Embodied Subjectivity, Contributions to Phenomenology 71, Switzerland: Springer, 2013, pp. 263-282.

SAN MARTín, Javier. "El contenido del cuerpo" en Investigaciones Fenomenológicas, vol. Monográfico 2: Cuerpo y Alteridad, Madrid: UNED, 2010, pp. 169187.

SEPP, Hans Rainer. “Apropiación por desapropiación. Paradojas de la reducción fenomenológica" en Escritos de Filosofía, Academia de Ciencias de Buenos Aires, No. 35-36, 1999. 
Serrano de Haro, Agustín. "Fundamentos del análisis fenomenológico del cuerpo" en La posibilidad de la fenomenología, Madrid: Editorial Complutense, 1997.

SVANEAEUS, Fredrik. "The phenomenology of chronic pain: embodiment and alienation", en Continental Philosophy Review 48 (2), J une 2015, pp. 107-122. 